\title{
Perfil dos usuários vivendo com HIVIAids atendidos em um Centro de Testagem e Aconselhamento no interior da Bahia: um estudo longitudinal retrospectivo
}

Daiana Alencar de Medeiros ${ }^{1}$ (D), Maria Augusta Vasconcelos Palácio ${ }^{1}$ (D), Luana Leandro Gois ${ }^{2}$ (D), Iukary Takenami ${ }^{1}$ (D)

\section{RESUMO}

Objetivo: Caracterizar o perfil clínico e epidemiológico dos usuários vivendo com HIV/Aids atendidos em um Centro de Testagem e Aconselhamento (CTA) localizado no município de Paulo Afonso, no interior da Bahia. Casuística e métodos: Estudo retrospectivo, observacional, baseado em dados secundários obtidos mediante consulta aos registros dos usuários cadastrados no serviço durante o período de 2002 a 2019 . Os dados foram tratados e analisados por estatística descritiva e inferencial. Resultados: Foram identificados 301 indivíduos vivendo com HIV/Aids, correspondendo a uma média de $12,4 \pm 9,5$ casos/ano; 58,4\% eram do sexo masculino com idade média de 40,6 $\pm 13,8$ anos. Os indivíduos mais afetados possuíam o ensino fundamental incompleto e eram provenientes de bairros periféricos. Dos 226 indivíduos avaliados laboratorialmente, 49 (21,7\%) foram diagnosticados na fase de Aids. Diferenças significativas foram observadas na contagem de linfócitos $\mathrm{T} C D 4^{+}$, razão entre os linfócitos $\mathrm{T} \mathrm{CD4}^{+} / \mathrm{CD} 8^{+}$ e linfócitos T CD45+ entre indivíduos vivendo com HIV e aqueles diagnosticados na fase de Aids ( $p<0,001)$. Conclusão: A taxa de detecção de pessoas vivendo com HIV/Aids aumentou nos últimos anos no município de Paulo Afonso, Bahia. Esse aumento no número de casos deve-se, possivelmente, aos avanços nos métodos diagnósticos, bem como da implementação do CTA na região. O perfil dos indivíduos avaliados segue a tendência nacional, com predomínio do sexo masculino, jovem, com ensino fundamental incompleto. Como esperado, indivíduos diagnosticados na fase Aids apresentam resultados laboratoriais diferentes dos indivíduos vivendo com HIV.

Palavras-chave: Síndrome de Imunodeficiência Adquirida; HIV; Epidemiologia; Perfil de Saúde.

Colegiado de Medicina, Universidade Federal do Vale do São Francisco, Paulo Afonso, (BA), Brasil.

Universidade Católica do Salvador, Salvador, (BA), Brasil. 


\section{INTRODUÇÃO}

A síndrome da imunodeficiência adquirida (Aids) é uma condição causada pelo vírus da imunodeficiência humana (HIV) que se caracteriza por um quadro de profunda deficiência imunológica, cujas principais consequências referem-se ao surgimento de infecções oportunistas e neoplasias malignas ${ }^{1,2}$. O Programa Conjunto das Nações Unidas sobre HIV/ Aids (UNAIDS) estima que existam cerca de 37,9 milhões de indivíduos vivendo com HIV/Aids ao redor do mundo ${ }^{3}$. No Brasil, 966.058 casos foram notificados desde o início da epidemia até junho de $2019^{4}$.

Segundo a Secretaria de Vigilância em Saúde (SVS), entre os anos de 2007 e 2019, houve um acréscimo de 300.496 casos novos de infecção por HIV notificados no Sistema de Informação de Agravos de Notificação (SINAN), sendo as regiões Sudeste $(45,6 \%)$, Sul $(20,1 \%)$ e Nordeste $(18,3 \%)$ as mais afetadas do país ${ }^{4}$. Apesar das taxas de detecção continuarem elevadas, nota-se que nos últimos anos a quantidade global de casos detectados no país diminuiu consideravelmente, com uma queda de $17,6 \%$ entre os anos de 2008 e 2018 . No entanto, a incidência dos casos não está igualmente distribuída entre os estados e regiões do país. As regiões Norte e Nordeste têm apresentado um aumento cada vez mais expressivo no número de casos. Entre os anos de 2008 a 2018, a taxa de detecção na região Norte aumentou de 20,6 para 25,1 casos por 100.000 habitantes, com um acréscimo estimado em $21,8 \%$. No Nordeste, nesse mesmo período, a taxa variou de 13,5 para 15,8 casos por 100.000 habitantes, evidenciando um acréscimo de $17 \%{ }^{4}$.

Amorim e Schlemper (2019) 5 acreditam que a mudança no cenário epidemiológico se deve à transição da incidência dos grandes centros urbanos para o interior do país, o que tornou a infecção por HIV/Aids mais prevalente entre indivíduos com baixa renda e/ou baixo nível de escolaridade. $\mathrm{O}$ cenário atual reflete a interiorização e pauperização da doença ${ }^{6}$. Embora haja estudos sobre o perfil epidemiológico da infecção por HIV/Aids em indivíduos residentes nas capitais ${ }^{7-9}$, os dados referentes às populações domiciliadas no interior dos estados são limitados, incluindo o município de Paulo Afonso, localizado no nordeste do estado da Bahia, a 471 $\mathrm{km}$ da capital Salvador ${ }^{10}$.
O município integra a Mesorregião Vale do São Francisco da Bahia, fazendo fronteira com os estados de Pernambuco, Alagoas e Sergipe. Segundo o Instituto Brasileiro de Geografia e Estatística (IBGE) de 2018, Paulo Afonso ocupa uma área territorial de $1.545,191 \mathrm{~km}^{2}$, com uma população estimada em 117.782 habitantes ${ }^{10}$. A assistência especializada a pessoas vivendo com HIV/Aids teve início no município em 2002, com a implantação do Centro de Testagem e Aconselhamento (CTA), seis anos após o primeiro registro oficial de caso de HIV/Aids no município ${ }^{11}$.

Embora a infecção por HIV, inicialmente, tenha ocorrido predominante em homens que fazem sexo com homens, observa-se que a taxa de detecção entre homens e mulheres heterossexuais está aumentando ${ }^{12}$. Atualmente, a taxa de detecção entre mulheres e homens no Brasil é de $2: 3^{4}$. Soares, Armindo e Rocha (2014) ${ }^{13}$ demostraram que as relações sexuais desprotegidas, compartiIhamento de seringas com indivíduos infectados, transfusões sanguíneas, acidentes com material perfurocortante contaminado e/ou pela via materno-infantil, em que mães infectadas transmitem o vírus ao filho durante o parto natural ou através do aleitamento materno, representam as principais formas de transmissão. Na corrente sanguínea, o vírus infecta, preferencialmente, os linfócitos $T$ $\mathrm{CD}^{+}{ }^{+}$, o que resulta em uma significativa destruição e redução dos títulos de linfócitos circulantes ${ }^{14}$. Considerando a importância destas células no combate às doenças infeciosas e/ou neoplasias, desenvolve-se ao longo da infecção uma grave imunodepressão que leva a doenças oportunistas e outras complicações. Essa fase da infecção caracteriza a AIDS e pode ser laboratorialmente demonstrada através da contagem de linfócitos $\mathrm{T} \mathrm{CD} 4{ }^{+}$abaixo de 200-350 células $/ \mathrm{mm}^{3}$ e carga viral plasmática elevada ${ }^{1,13}$.

Face ao desafio de prevenir e controlar essa epidemia e, considerando a interiorização e pauperização do HIV, o conhecimento dos padrões de distribuição epidemiológica da doença em diferentes regiões brasileiras é imprescindível para entender o processo saúde-doença, bem como o desenvolvimento de estratégias que visem aumentar a prevenção, detecção de casos, tratamento e controle do HIV/Aids em diversas regiões. De modo contrário, a ausência de políticas de prevenção mais 
específicas pode acentuar a interiorização da epidemia, alcançando cada vez mais municípios menores e afastados dos grandes centros. Nesse sentido, o presente estudo teve como objetivo caracterizar o perfil clínico e epidemiológico dos usuários que vivem com HIV/Aids atendidos em um CTA do município de Paulo Afonso, localizado no interior do estado da Bahia.

\section{CASUÍSTICA E MÉTODOS}

Trata-se de um estudo longitudinal, retrospectivo, observacional, baseado em dados secundários obtidos mediante consulta aos registros dos usuários cadastrados no sistema informatizado do Centro de Testagem e Aconselhamento/Serviço de Assistência Especializada (CTA/SAE), durante o período de 2002 a 2019, no município de Paulo Afonso, Bahia. O CTA/SAE é um centro de acompanhamento de infecções sexualmente transmissíveis (ISTs), incluindo HIV/Aids, que realiza ações de prevenção, acompanhamento assistencial e tratamento aos usuários encaminhados e/ou aqueles que buscam atendimento no centro.

A população estudada foi composta por 301 usuários cadastrados no CTA/SAE que receberam diagnóstico positivo para HIV/Aids no período de 1996 a 2019. Foi aplicado como critério de exclusão, a não completude dos dados essenciais ao estudo nos prontuários. $O$ projeto foi aprovado pelo Comitê de Ética em Pesquisa (CEP) da Universidade Federal do Vale do São Francisco (UNIVASF), sob parecer $n^{\circ}$ 3.451.026, atendendo à Resolução no 196/96 do Conselho Nacional de Saúde.

O instrumento utilizado para a coleta de dados nos prontuários foi um formulário não validado, mas que foi elaborado com base nas fichas de admissão do CTA/SAE. As variáveis utilizadas no formulário corresponderam às informações coletadas no momento do diagnóstico, sendo estas relativas ao sexo, idade, bairro, município, estado civil, escolaridade, ano de diagnóstico, carga viral (cópias $/ \mathrm{mL}$ ), valor absoluto e relativo da contagem de linfócitos $\mathrm{T} \mathrm{CD}^{+}{ }^{+}, \mathrm{TCD}^{+}$, contagem de linfócitos $\mathrm{T} C D 45^{+}$e razão de linfócitos $\mathrm{T} \mathrm{CD} 4^{+} / \mathrm{CD}^{+}$. Os dados foram coletados por um único pesquisador, treinado para extrair as informações dos prontuários de usuários do CTA/SAE, os quais foram digitados e consolidados no programa Microsoft ${ }^{\circledR}$ Office
Excel 2003, com dupla digitação e checagem da consistência.

Os dados obtidos foram analisados por meio do software GraphPad Prism v.8 (GraphPad Software, San Diego, CA, EUA). Para análise descritiva de variáveis categóricas foram utilizados mapas e tabelas, informados em frequência absoluta (n) e relativa (\%). As variáveis quantitativas foram descritas pela média e desvio-padrão (DP). Os testes qui-quadrado ou o teste exato de Fisher foram utilizados para avaliação da associação entre as variáveis categóricas. $O$ teste de Pearson foi empregado para analisar a correlação entre os resultados laboratoriais. Para a análise das diferenças entre os grupos estudados, utilizou-se o teste t de Student. As diferenças foram consideradas estatisticamente significantes para valores de $p<0,05$.

\section{RESULTADOS}

Foram analisados 301 registros de admissão no CTA/SAE, diagnosticados no período de 1996 a 2019 e correspondendo a uma média de 12,5 \pm 9,6 casos/ano. Observa-se que ao longo dos anos houve um aumento significativo no diagnóstico de HIV/Aids, especialmente após a implementação do CTA/SAE no ano de 2002, no município de Paulo Afonso ( $r=0,862, p<0,001$, Figura 1).

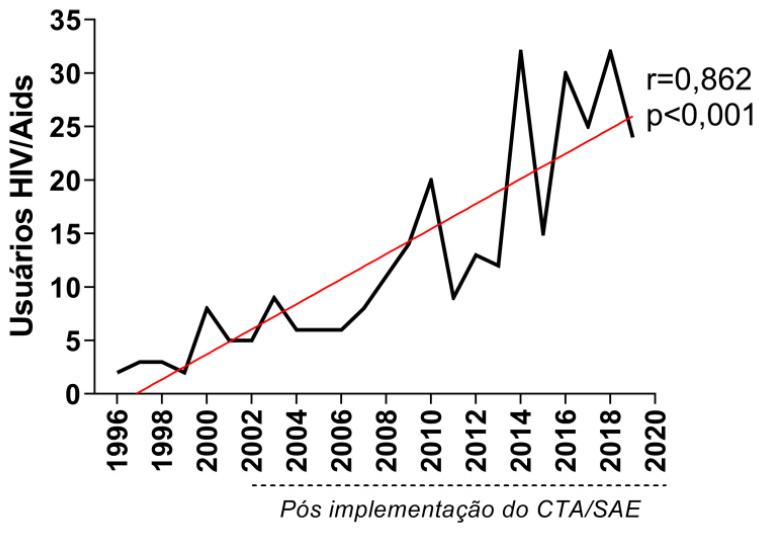

Figura 1: Usuários vivendo com HIV/Aids cadastrados no CTA/SAE do município de Paulo Afonso-BA, segundo o ano de diagnóstico $(\mathrm{N}=301)$. HIV = Vírus da Imunodeficiência Humana; Aids = Síndrome da Imunodeficiência Adquirida; $\mathrm{CTA}=$ Centro de Testagem e Aconselhamento; SAE = Serviço de Assistência Especializada. 
Cem $(33,2 \%)$ dos 301 indivíduos vivendo com HIV residem em municípios próximos. A maioria dos casos foi procedente dos municípios de Jeremoabo $(n=18,18 \%)$, Delmiro Gouveia $(n=15,15 \%)$ e Santa Brígida $(n=11,11 \%)$, todos localizados a $85,5 \mathrm{~km}, 39,1 \mathrm{~km}$ e 59,8 km de distância de Paulo Afonso, respectivamente (Figura $2 \mathrm{~A})$. Dois $(0,7 \%)$ casos não possuíam dados referentes ao local de residência. Os demais casos $(n=199,66,1 \%)$ possuíam residência fixa no município de Paulo Afonso. Os bairros Centro e Tancredo Neves III concentram o maior número de indivíduos vivendo com HIV, com $27,14 \%(n=54)$ e $19,6 \%(n=39)$, respectivamente. Os bairros com o menor índice de casos confirmados foram Amaury Alves de Menezes, Benone Resende, General Dutra, Jardim Aeroporto, Jardim Bahia, Oliveira Lopes, Santa Inês, Siriema II e Vila Nobre com apenas um caso em cada local $(0,5 \%)$, como evidenciado pela Figura 2B.

Para as análises seguintes foram excluídos os indivíduos com mais de $5 \%$ de não completude das informações nos prontuários eletrônicos. Assim, dos 301 casos, 75 (24,9\%) foram excluídos. No entanto, nenhuma diferença estatística foi observada entre os dois grupos nas variáveis sexo, idade, estado civil e escolaridade ( $p>0,05)$.

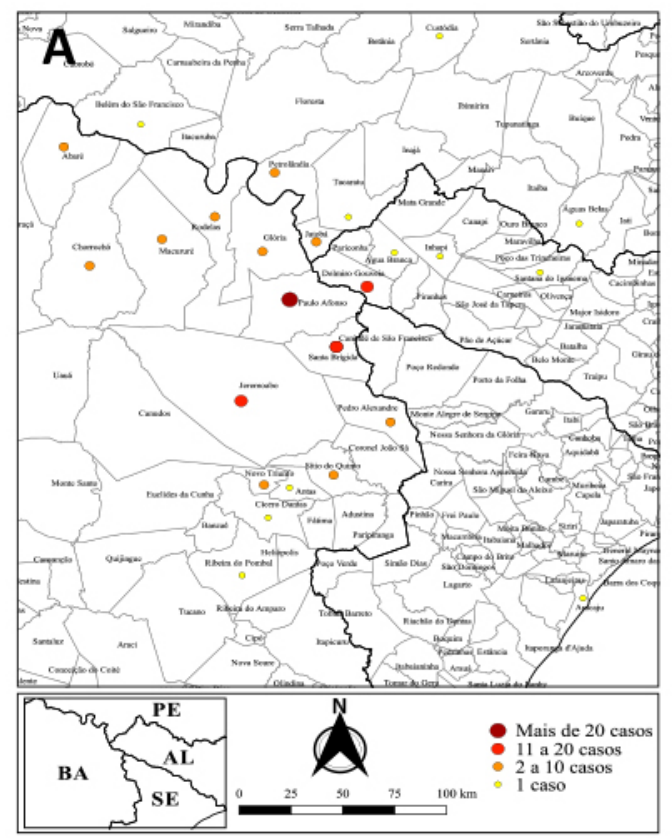

Dos $226(75,1 \%)$ prontuários analisados, houve uma prevalência de 58,4\% $(n=132)$ de indivíduos do sexo masculino, com uma razão cerca de $(1,4: 1)$, idade média de $40,6 \pm 13,8$ anos, sendo a faixa etária mais frequente de 31 a 45 anos. Quanto ao estado civil, $51 \%(n=107)$ eram solteiros, $42,5 \%$ $(n=91)$ tinham o ensino fundamental incompleto e $70,5 \%(n=158)$ possuíam residência fixa no município de Paulo Afonso (Tabela 1). Analisando o município de residência, observa-se que $76,9 \%(n=100)$ e $37,1 \%(n=46)$ dos homens residem em Paulo Afonso e possuem o ensino fundamental incompleto. Enquanto $61,7 \%(n=58)$ e $50 \%(n=45)$ das mulheres residem no mesmo município e possuem o ensino fundamental incompleto. Essa diferença entre os sexos foi estatisticamente significante, $p=0,023$ e $p=0,015$, respectivamente (dados não mostrados).

Dos 226 indivíduos vivendo com HIV, 49 $(21,7 \%)$ casos foram diagnosticados na fase de Aids, com contagem de linfócitos $\mathrm{T} \mathrm{CD}^{+}$menor do que 200 células $/ \mathrm{mm}^{3}$, média de $121,9 \pm 56,1$ células $/ \mathrm{mm}^{3}$. Por outro lado, $177(78,3 \%)$ apresentavam contagem de linfócitos $\mathrm{T} \mathrm{CD4}^{+}$maior do que 200 células $/ \mathrm{mm}^{3}$, média de $559,6 \pm 338$ células $/ \mathrm{mm}^{3}$, o que demonstrou haver diferença estatística significativa entre os grupos ( $p<0,001$, Tabela 2$)$.

\begin{tabular}{lc}
\hline \multicolumn{1}{c}{ Paulo Afonso } & $\begin{array}{c}\text { Total, } \mathbf{N = 1 9 9} \\
\mathbf{n}(\%)\end{array}$ \\
\hline Alves de Souza & $2(1,01)$ \\
Amaury Alves de Menezes & $1(0,5)$ \\
Barroca & $4(2,01)$ \\
Benone Resende & $1(0,5)$ \\
BTN 1 & $6(3,02)$ \\
BTN 2 & $21(10,55)$ \\
BTN 3 & $39(19,6)$ \\
Caminho dos Lagos & $2(1,01)$ \\
Centro & $54(27,14)$ \\
Centenário & $15(7,54)$ \\
CHESF & $7(3,52)$ \\
Cleriston Andrade & $3(1,51)$ \\
General Dutra & $1(0,5)$ \\
Jardim Aeroporto & $1(0,5)$ \\
Jardim Bahia & $1(0,5)$ \\
Moxotó & $4(2,01)$ \\
Oliveira Lopes & $1(0,5)$ \\
Perpétuo Socorro & $4(2,01)$ \\
Prainha & $9(4,52)$ \\
Rodoviários & $3(1,51)$ \\
Santa Inês & $1(0,5)$ \\
Săo Vicente & $2(1,01)$ \\
Siriema I & $3(1,51)$ \\
Siriema II & $1(0,5)$ \\
Vila Nobre & $1(0,5)$ \\
\hline &
\end{tabular}

*Quatro $(2,01 \%)$ voluntários foram registrados como moradores de rua e oito $(4,02 \%)$ não possuíam registro do bairro de moradia em Paulo Afonso. BTN = Bairro Tancredo Neves; CHESF = Companhia Hidrelétrica do São Francisco.

Figura 2: Distribuição dos usuários vivendo com HIV/Aids cadastrados no CTA/SAE, segundo o município de residência (A) e bairro no município de Paulo Afonso-BA (B). 
Tabela 1

Características sociodemográficas dos usuários vivendo com HIV cadastrados no CTA/SAE do município de Paulo Afonso, conforme a carga viral.

\begin{tabular}{|c|c|c|c|c|}
\hline \multirow[t]{2}{*}{ Características } & $\begin{array}{c}<200 \text { (cél./mm3) } \\
n=49\end{array}$ & $\begin{array}{c}>200 \text { (cél./mm3) } \\
n=177\end{array}$ & $\begin{array}{c}\text { Total } \\
\mathbf{N}=226\end{array}$ & \multirow[t]{2}{*}{ p-valor } \\
\hline & \multicolumn{3}{|c|}{ n (\%) } & \\
\hline \multicolumn{5}{|l|}{ Sexo } \\
\hline Masculino & $25(51)$ & $107(60,5)$ & $132(58,4)$ & 0,248 \\
\hline Feminino & $24(49)$ & $70(39,5)$ & $94(41,6)$ & \\
\hline \multicolumn{5}{|l|}{ Idade } \\
\hline 1 a 15 anos & - & $4(2,3)$ & $4(1,8)$ & 0,166 \\
\hline 16 a 30 anos & $8(16,3)$ & $41(23,2)$ & $49(21,7)$ & \\
\hline 31 a 45 anos & $18(36,7)$ & $79(44,6)$ & $97(42,9)$ & \\
\hline 46 a 60 anos & $16(32,7)$ & $43(24,3)$ & $59(26,1)$ & \\
\hline$>60$ anos & $7(14,3)$ & $10(5,6)$ & $17(7,5)$ & \\
\hline \multicolumn{5}{|l|}{ Município de residênciaa } \\
\hline Paulo Afonso & $35(71,4)$ & $123(70,3)$ & $158(70,5)$ & 0,862 \\
\hline Outras localidades & $14(28,6)$ & $52(29,7)$ & $66(29,5)$ & \\
\hline \multicolumn{5}{|l|}{ Estado civilb } \\
\hline Solteiro(a) & $21(45,6)$ & $86(52,4)$ & $107(51)$ & 0,003 \\
\hline Casado(a)/União estável & $13(28,3)$ & $67(40,9)$ & $80(38,1)$ & \\
\hline Viúvo(a) & $3(6,5)$ & $3(1,8)$ & $6(2,8)$ & \\
\hline Divorciado(a)/Separado(a) & $9(19,6)$ & $8(4,9)$ & $17(8,1)$ & \\
\hline \multicolumn{5}{|l|}{ Escolaridadec } \\
\hline Analfabeto(a) & $8(16,7)$ & $8(4,8)$ & $16(7,5)$ & 0,061 \\
\hline $1^{\circ}$ grau incompleto & $19(39,6)$ & $72(43,4)$ & $91(42,5)$ & \\
\hline $1^{\circ} \mathrm{grau}$ completo & $2(4,2)$ & $18(10,8)$ & $20(9,3)$ & \\
\hline $2^{\circ} \mathrm{grau}$ incompleto & $3(6,2)$ & $9(5,4)$ & $12(5,6)$ & \\
\hline $2^{\circ}$ grau completo & $9(18,7)$ & $43(25,9)$ & $52(24,3)$ & \\
\hline Superior & $7(14,6)$ & $16(9,7)$ & $23(10,8)$ & \\
\hline
\end{tabular}

Dois usuários com $>200$ células $/ \mathrm{mm}^{3}$ não possuíam o município de residência registrado no prontuário.

'Três usuários com < 200 células $/ \mathrm{mm}^{3}$ e $13 \mathrm{com}>200$ células $/ \mathrm{mm}^{3}$ não possuíam o estado civil registrado no prontuário.

cUm usuário com $<200$ células $/ \mathrm{mm}^{3}$ e $11 \mathrm{com}>200$ células $/ \mathrm{mm}^{3}$ não possuíam a escolaridade registrada no prontuário.

Tabela 2

Características laboratoriais dos usuários vivendo com HIV/Aids cadastrados no CTA/SAE do município de Paulo Afonso, conforme contagem de linfócitos $\mathrm{T} \mathrm{CD}^{+}$.

\begin{tabular}{|c|c|c|c|c|}
\hline \multirow{2}{*}{ Exames laboratoriais } & $\begin{array}{c}<200 \text { (cél./mm3) } \\
n=49\end{array}$ & $\begin{array}{c}>200 \underset{n=177}{(\text { cél./mm3) }} \\
\text { ( } 177\end{array}$ & $\begin{array}{l}\text { Total } \\
\mathbf{N}=226\end{array}$ & \multirow{2}{*}{ p-valor } \\
\hline & \multicolumn{3}{|c|}{ Média \pm DP } & \\
\hline T CD4+ (células/mm³) & $121,9 \pm 56,1$ & $559,6 \pm 338,0$ & $464,7 \pm 350,3$ & $<0,001$ \\
\hline T CD8+ (células/mm³) & $930,2 \pm 519,8$ & $1.090 \pm 582,4$ & $1.056 \pm 572,1$ & 0,083 \\
\hline Relação T CD4+/CD8+ & $0,2 \pm 0,14$ & $0,6 \pm 0,6$ & $0,5 \pm 0,6$ & $<0,001$ \\
\hline T CD45+ (células $\left./ \mathrm{mm}^{3}\right)^{\mathrm{a}}$ & $1.424 \pm 620,5$ & $2.277 \pm 910,5$ & $2.087 \pm 924,4$ & $<0,001$ \\
\hline Carga viral (cópias/mL) & $99.366 \pm 325.430$ & $36.580 \pm 174.074$ & $53.405 \pm 225.336$ & 0,127 \\
\hline
\end{tabular}

aSeis usuários com > 200 células $/ \mathrm{mm}^{3}$ não possuíam a contagem de linfócitos T CD45+ registrado no prontuário. ' ${ }^{\circ}$ Oito usuários com < células $/ \mathrm{mm}^{3}$ e $65 \mathrm{com}>200$ células $/ \mathrm{mm}^{3}$ possuíam carga viral indetectável.

DP = desvio-padrão. 
Ademais, observa-se que $40,9 \%(n=67)$ e $28,3 \%$ $(n=13)$ apresentam-se casados/união estável entre aqueles com contagem de linfócitos > 200 e < 200 células $/ \mathrm{mm}^{3}$, respectivamente. Essa diferença entre os grupos foi estatisticamente significante com $p=0,003$. Por outro lado, nenhuma diferença entre o sexo, idade, município de residência e escolaridade foi observada entre os indivíduos vivendo com HIV daqueles que foram diagnosticados com Aids no momento de ingresso no CTA/SAE ( $p>0,05$, Tabela 1).

Além da contagem de linfócitos $\mathrm{T} \mathrm{CD}^{+}$, outras diferenças significativas podem ser observadas, tais como a razão de linfócitos $\mathrm{T} \mathrm{CD} 4^{+} / \mathrm{CD}^{+}{ }^{+}$e contagem de linfócitos $\mathrm{T} \mathrm{CD} 45^{+}$, ambos com $\mathrm{p}<0,001$, entre os indivíduos com contagem de linfócitos $>200$ e < 200 células $/ \mathrm{mm}^{3}$ (Tabela 2 ). Curiosamente, quando se avalia os exames laboratoriais estratificados por sexo, observa-se que os homens apresentam diferença estatisticamente significativa na contagem total de linfócitos T CD8 ${ }^{+}$(homens: $1.126 \pm 595,2$ células $/ \mathrm{mm}^{3}$; mulheres: $955,9 \pm 525,2$ células/ $\mathrm{mm}^{3}$ ) e entre aqueles que apresentam $>350$ linfócitos $\mathrm{T} \mathrm{CD}^{+} / \mathrm{mm}^{3}$ (homens: $1.153 \pm 584,4$ células/ $\mathrm{mm}^{3}$; mulheres: $994,7 \pm 512,7$ células $/ \mathrm{mm}^{3}$ ) com $p=0,027$ e $p=0,04$, respectivamente. Observam-se também diferenças significativas na contagem de linfócitos $\mathrm{T} \mathrm{CD}^{+} 5^{+}$(homens: $2.278 \pm 989$ células $/ \mathrm{mm}^{3}$; mulheres: $1.856 \pm 878,5$ células $/ \mathrm{mm}^{3}$; $\mathrm{p}=0,001$; dados não mostrados).

Conforme esperado, as variáveis, contagem de linfócitos $\mathrm{T} \mathrm{CD4}^{+}$(valor absoluto e relativo) e razão entre os linfócitos $\mathrm{T} \mathrm{CD} 4^{+} / \mathrm{CD} 8^{+}$demonstraram associação linear negativa quando comparadas com a carga viral do paciente $(r=-0,163, p=0,043$; $r=-0,206, p=0,01$ e $r=-0,189, p=0,018$, respectivamente; Figura 3). Por outro lado, observa-se uma associação linear positiva quando se avalia a contagem de linfócitos T CD8+ (células $\left./ \mathrm{mm}^{3}\right)(r=0,165$, $p=0,04)$.
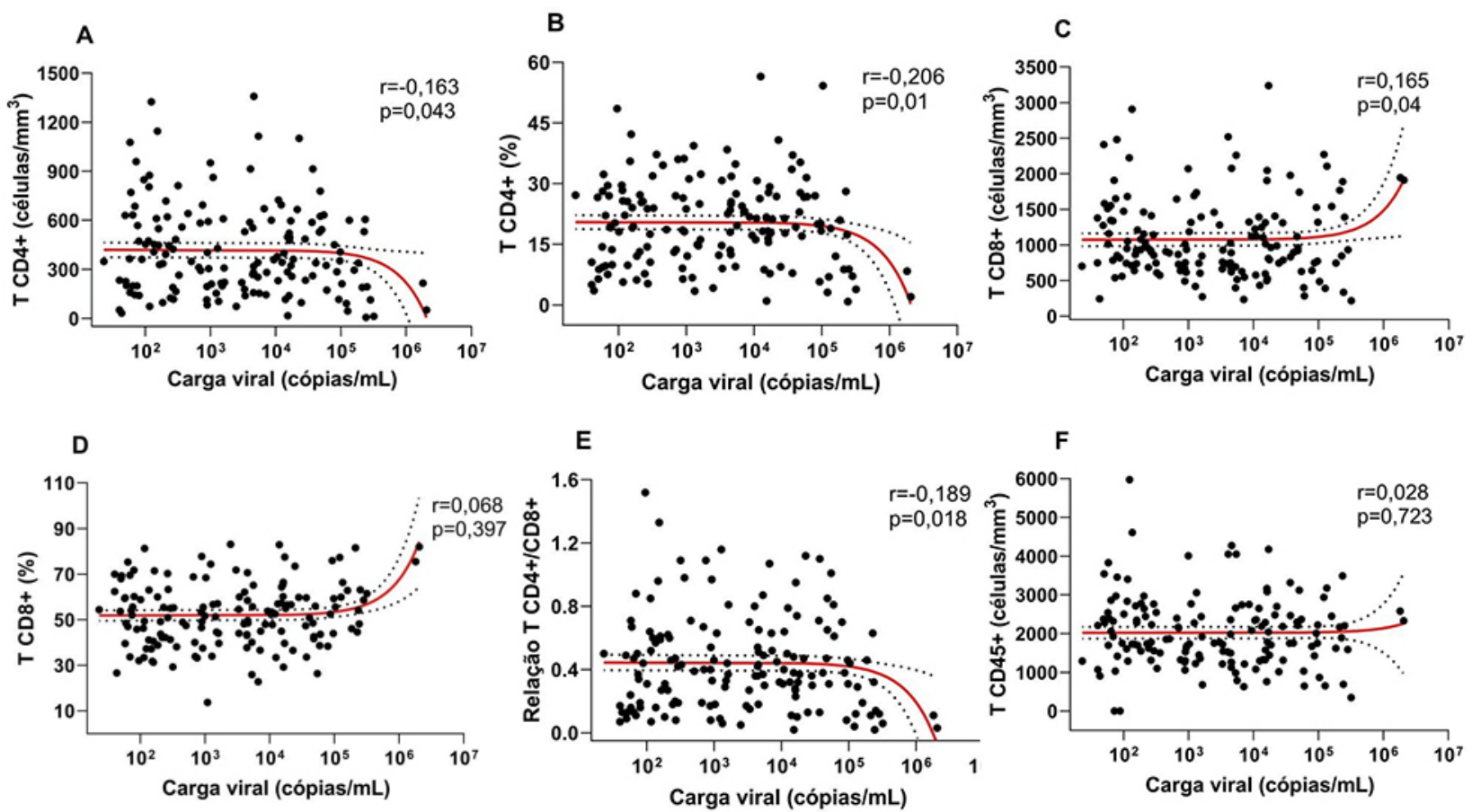

Figura 3: Correlação entre a carga viral e os resultados laboratoriais dos linfócitos $T C D 4^{+}(A$ e $B)$, $T$ CD8 ${ }^{+}(C$ e $D)$, relação $T$ $\mathrm{CD} 4 / \mathrm{CD}^{+}(\mathrm{E})$ e T CD45 $(\mathrm{F})$. 


\section{DISCUSSÃO}

O presente estudo permitiu avaliar o perfil dos usuários de um Serviço de Assistência Especializada em HIV/Aids no município de Paulo Afonso, localizado no interior do estado da Bahia. Paulo Afonso é um município de médio porte que possui pouco mais de 100 mil habitantes. No entanto, sua localização privilegiada, fazendo divisa com três estados do Nordeste, torna-o centro de referência para os municípios vizinhos de pequeno porte. De acordo com os estudos de Oliveira et al. (2019) ${ }^{15}$ e Prado e Castilho (2009) ${ }^{6}$, observa-se que assim como ocorreu em Paulo Afonso, houve um aumento no número de casos positivos para HIV/Aids no interior dos estados de São Paulo e Sergipe, respectivamente. Em conjunto, esses resultados confirmam a tendência de interiorização da epidemia HIV/Aids, especialmente, nos municípios de pequeno e médio porte, resultando na maior disseminação espacial do HIV no território brasileiro. Ademais, tais achados estão de acordo com a tendência regional, em que se nota um aumento de $17 \%$ na detecção de casos no ano de 2018 em relação ao ano de $2008^{4}$.

Este fenômeno apresenta-se como um importante problema de saúde pública, causando novas dificuldades no controle da epidemia HIV/Aids, uma vez que esses locais se mostram mais desassistidos e com menor renda per capita $5^{16}$. Embora haja um aumento no número de casos, deve-se considerar outras possibilidades para este aumento, tais como a subnotificação, migração dos casos para a capital nos anos anteriores, a implantação do CTA/SAE e a utilização do teste rápido como método de triagem inicial em 2009; conquistas que possibilitaram ampliar a assistência em saúde e a eficiência dos diagnósticos fornecidos ${ }^{17}$.

Em relação ao sexo, observou-se uma predominância do sexo masculino, o que também pode ser evidenciado pela tendência global do país $(69 \%)^{4}$ e em outros estudos reportados na literatura ${ }^{5,15}$. Essa realidade é justificada pelo fato do homem ter um comportamento mais susceptível, com maior quantidade de parceiras(os) sexuais e menor adesão ao uso do preservativos ${ }^{12,16}$. Não obstante, observa-se uma tendência crescente na detecção de mulheres vivendo com HIV/Aids, reduzindo a razão de homens e mulheres com HIV, a exemplo dos resultados encontrados no estudo.
Essa tendência é relatada por diversos autores, em que se observa uma feminização da epidemiologia do HIV/Aids ${ }^{16,18,19}$. Essa teoria mostra que ao contrário do que ocorreu nos primórdios da epidemia, em que o segmento mais acometido eram homens homossexuais e bissexuais, no presente, as mulheres apresentam maiores taxas de infecção, refletindo na progressiva queda nacional da razão de sexo, reduzindo de 6:1 em 1990 para 2:3 em $2018^{4,16,18}$. A feminização da epidemiologia do HIV/ Aids pode ser explicada por diversos fatores, entre eles a violência sexual, maior número de parceiros sexuais e heterossexualização do perfil das pessoas vivendo com HIV/Aids, principal grupo acometido atualmente ${ }^{19}$. Além disso, a sociedade ainda é culturalmente marcada pela subserviência da mulher ao homem que, muitas vezes, a impede de ter autonomia sobre si e sobre seus relacionamentos, não garantindo o direito de escolha pelo uso de preservativos, assim como desfrutar de relacionamentos fiéis ${ }^{20}$. Outro ponto que deve ser enfatizado é o alto índice encontrado de mulheres casadas vivendo com HIV. Esse resultado reforça a vulnerabilidade feminina diante de relacionamentos infiéis e abusivos, os quais promovem a falsa ideia de ausência de riscos para ISTs e evitam que mulheres tomem os cuidados necessários ${ }^{7,20}$.

Ao ser analisada a faixa etária mais prevalente entre os casos, observa-se que os indivíduos entre 31 e 49 anos foram prevalentes, apresentando uma pequena discordância dos valores nacionais evidenciados pelo boletim epidemiológico do Ministério da Saúde ${ }^{4}$, cuja faixa etária predominante foi a compreendida entre 20 e 34 anos. No entanto, os resultados obtidos são similares aos apresentados por Amorim e Schlemper (2019) ${ }^{5}$, em um estudo realizado no município de Joaçaba, Santa Catarina, cujo grupo mais prevalente foram indivíduos do sexo masculino entre 31 e 50 anos. De acordo com Brito, Castilho e Szwarcwald et al. (2001) ${ }^{16}$, o segmento populacional entre 20 e 40 anos representa a maior parte dos indivíduos sexualmente ativos, logo, eles estariam mais suscetíveis à infecção pelo HIV, uma vez que a principal via de infecção atualmente é a sexual. Ademais, vários autores relatam uma tendência atual, principalmente entre adultos jovens, de subvalorizar a gravidade da doença e, consequentemente, reduzir cuidados, devido à evolução da terapia antirretroviral que permite cada vez mais 
viver com HIV/Aids como uma doença crônica com menores agravos à qualidade de vida, além da atual recomendação de profilaxia pré-exposição ${ }^{8}$.

Quando relacionado o número de casos com a escolaridade e condições socioeconômicas, observou-se que o perfil predominante foi o de indivíduos com baixa escolaridade $(42,5 \%$; ensino fundamental incompleto) e condições socioeconômicas evidenciadas por uma concentração importante de casos em bairros periféricos (bairro Tancredo Neves I, II e Prainha). Esse resultado é condizente com o fenômeno atual de pauperização, caracterizado por uma proporção cada vez maior de indivíduos vivendo com HIV/Aids e que possuem menor nível de escolaridade e condição social ${ }^{5,16}$. Essa tendência de pauperização do perfil de indivíduos vivendo com HIV/Aids pode ser justificada pelo fato desses indivíduos possuírem uma menor assistência em saúde, maior suscetibilidade devido ao comportamento de risco (uso de drogas injetáveis e não adesão à utilização do preservativo), menor acesso às informações de prevenção e tratamento, início mais precoce das atividades sexuais e, portanto, menor maturidade e autonomia diante de um relacionamento $7,12,16,21$.

Ao se observar a quantidade de indivíduos vivendo com Aids no estudo, percebe-se que o número de casos representou menos de um quarto da amostra $(21,7 \%)$, o que evidencia uma maior sensibilização das pessoas em procurar os serviços de saúde precocemente e se autocuidar, assim como mostra uma boa efetividade do CTA/SAE em realizar diagnósticos precoces através de atividades comunitárias, nas quais são ofertados testes rápidos para toda a população-alvo ${ }^{22}$. Além disso, nota-se que $40,8 \%$ entre os indivíduos atendidos no CTA/ SAE possuem uma duração de acompanhamento que varia entre sete a 19 anos (dados não mostrados), o que demonstra um aumento importante na sobrevida desses pacientes. Embora a doença ainda permaneça letal, os avanços científicos e as novas condutas na terapia antirretroviral têm contribuído com a condição de cronicidade do HIV/Aids ${ }^{16,23}$.

Esse aumento da expectativa de vida e redução de casos de Aids é similar a outros estudos que mostram que tais conquistas foram possíveis graças aos avanços tecnológicos e científicos em relação ao HIV/Aids, permitindo maior eficiência na prevenção com políticas educativas e profilaxia pós-exposição, diagnóstico precoce através da implementação dos testes rápidos, introdução à terapia antirretroviral (TARV) concomitante ao diagnóstico da infecção pelo HIV, assistência integral e holística a esses indivíduos ${ }^{16,19,24}$.

Verificou-se que os níveis de linfócitos $T$ $\mathrm{CD}^{+}$estavam diretamente relacionados a carga viral e isso deve-se ao importante papel dessas células no combate às infecções causadas por vírus. Portanto, na tentativa de eliminar o vírus, quanto maior a carga viral, maiores serão os níveis detectados dessas células ${ }^{1,25}$. As células T CD4 ${ }^{+}$, por sua vez, apresentaram uma relação inversamente proporcional com a carga viral, o que pode ser justificada pela história natural da infecção pelo HIV, na qual esses linfócitos são os principais alvos da infecção pelo vírus ${ }^{1,13}$.

Estudos têm demonstrado uma disparidade importante na proporção de linfócitos $\mathrm{T}$ em função das variáveis sexo, idade e etnia ${ }^{26}$. Tal fato pode ser evidenciado pelo presente trabalho, em que diferenças laboratoriais significativas foram identificadas entre os níveis de linfócitos $\mathrm{T} \mathrm{CD}^{+}$e $\mathrm{T}$ $\mathrm{CD}_{4} 5^{+}$na abordagem por sexo. De acordo com o estudo realizado na província chinesa, Yunnan, a partir da análise da contagem de células por sexo, a média dos valores absolutos de linfócitos T CD4 ${ }^{+}$ e linfócitos $T C D 45^{+}$foram maiores nas mulheres do que nos homens vivendo com HIV/Aids ${ }^{25,27}$. A literatura sobre o comportamento imunológico do HIV entre os diferentes sexos ainda não está totalmente esclarecida. No entanto, tais diferenças podem ser resultantes de expressões gênicas específicas associadas a genes localizados no cromossomo $\mathrm{X}^{27}$.

Em relação à razão de linfócitos $\mathrm{T} \mathrm{CD} 4^{+} / \mathrm{CD} 8^{+}$ entre os indivíduos estudados, percebe-se que ela esteve abaixo de um na maioria dos casos. De acordo com Passos et al. (2020)25, a menor razão (ou $<1$ ) entre linfócitos $\mathrm{T} \mathrm{CD}^{+} / \mathrm{CD}^{+}$é um indicador de disfunção imunológica persistente e seria resultante de uma expansão continuada de novos linfócitos $\mathrm{T} \mathrm{CD}^{+}$altamente especializados e senescentes que levariam a um ritmo retardado de recuperação do número de linfócitos $\mathrm{T} \mathrm{CD}^{+}$e $\mathrm{T} \mathrm{CD} 8^{+}$ virgens e piora dos estágios de imunossupressão. Assim, embora a ausência de linfócitos T CD4 ${ }^{+}$ cause prejuízo funcional, a expansão dos linfócitos $\mathrm{T} \mathrm{CD}^{+}$seria mais importante na relação linfócitos $\mathrm{T} \mathrm{CD}^{+} / \mathrm{CD}^{+25}$. 
O conhecimento sobre os indivíduos vivendo com HIV/Aids, a exemplo do número de casos, adesão, maior acesso a TARV e o controle da carga viral são metas preconizadas pela UNAIDS como estratégias de controle da transmissão e redução dos $\operatorname{casos}^{28}$. Além das medidas discutidas acima, outro ponto válido que deve ser ressaltado na criação de políticas públicas para erradicação do HIV/Aids é a necessidade de conhecer os bairros com o maior número de casos dentro de um município, informação essa que representa um dos pilares do atual trabalho. Assim, os resultados obtidos, embora incipientes, podem enriquecer o serviço CTA/SAE, permitindo que a unidade amplie seu campo de atuação e desenvolva ações que realmente assistam os grupos de indivíduos mais afetados. Ademais, é plausível considerar que os resultados encontrados no estudo possam ser extrapolados para outros municípios com características similares a Paulo Afonso. Contudo, é importante que os dados sejam interpretados com cautela, pois algumas limitações foram observadas no estudo como a ausência de dados sobre o tratamento e evolução destes pacientes, a não validação do instrumento de coleta de dados e a coleta de dados realizados por um único pesquisador.

Por fim, o estudo traz contribuições importantes para a ciência, ratificando a tendência nacional de interiorização e pauperização da doença, sinalizando a necessidade de ampliar o conhecimento sobre a situação de saúde de uma determinada região para direcionar ações de cuidado em saúde mais efetivas, sobretudo no âmbito do SUS. Ademais, constitui-se como uma importante fonte de dados para os profissionais de saúde que estão na prática, atuando diretamente na prevenção e no cuidado às pessoas com HIV/Aids. A partir desses resultados, percebe-se a relevância de investir em pesquisas que avaliem o tratamento e a evolução dos pacientes atendidos no CTA/SAE.

\section{CONCLUSÃO}

Houve um aumento na taxa de deteç̧ão de pessoas vivendo com HIV/Aids nos últimos 24 anos no município de Paulo Afonso, Bahia, sendo a população masculina o grupo mais acometido. Esse acréscimo, possivelmente, foi resultante, em grande parte, dos avanços nos métodos diagnósticos, assim como devido à instalação do CTA/SAE na região. As características epidemiológicas do HIV/ Aids no município seguem a tendência nacional de interiorização, feminização e pauperização do perfil de indivíduos que vivem com a doença. Tal realidade evidencia a necessidade de criação de políticas públicas mais efetivas e abrangentes voltadas para esse grupo de indivíduos.

\section{REFERÊNCIAS}

1. Abbas AK, Lichtman, AH, Pillai S. Imunologia celular e molecular. Rio de Janeiro: Elsevier; 2015

2. Kasper DL, Hauser SL, Jameson JL, Fauci AS, Longo DL, Loscalzo J. Medicina Interna de Harrison. Porto Alegre: AMGH; 2017

3. Programa Conjunto das Nações Unidas sobre HIV/ AIDS. Relatório informativo: estatísticas globais sobre HIV [Internet]. 2019. Brasilia: UNAIDS; 2019 [citado 2020 maio 17]. Disponível em: https://unaids.org.br/ wp-content/uploads/2019/11/2019_UNAIDS_WAD2019_ FactSheet.pdf

4. Ministério da Saúde (BR). HIV AIDS 2019. Boletim Eletrônico Epidemiológico da Secretaria de Vigilância em Saúde. Número especial v.49, n.53 Brasília: Ministério da saúde; 2019 [citado 2020 maio 17]. Disponível em: http://www.aids.gov.br/pt-br/pub/2019/ boletim-epidemiologico-de-hivaids-2019

5. Amorim LT, Schlemper JBR. HIV/AIDS in small cities in Midwest Santa Catarina, south of Brazil: Clinical and epidemiological aspects, opportunistic infections. Rev Soc Bras Med Trop [online]. 2019; 52:e20180430.

6. Prado RR, Castilho EA. A epidemia de aids no Estado de São Paulo: uma aplicação do modelo espaço-temporal bayesiano completo. Revista da Sociedade Brasileira de Medicina Tropical [online]. 2009; 42(5):537-542. doi: $10.1590 /$ S0037-86822009000500011

7. Pinto VM, Basso CR, Barros CRS, Gutierrez EB. Fatores associados às infecções sexualmente transmissíveis: inquérito populacional no município de São Paulo, Brasil. Rev Ciência \& Saúde Coletiva [online]. 2018; 23(7):24232432. doi: $10.1590 / 1413-81232018237.206020161$

8. Kerr L, Kendall C, Guimarães MDC, Mota RS, Veras MA, Dourado I, et al. HIV prevalence among men who have sex with men in Brazil: results of the 2 nd national survey using respondent-driven sampling. Medicine [online]. 2018; 97:S1. doi: 10.1097/MD.0000000000010573

9. Dartora WJ, Ânflor EP, Silveira LRP. Prevalência do HIV no Brasil 2005-2015: dados do Sistema Único de Saúde HIV. Revista Cuidarte [online]. 2017; 8(3):191928. doi: 10.15649/cuidarte.v8i3.462

10. Instituto Brasileiro de Geografia e Estatística. Cidades e Estados [Internet]. 2019. Rio de Janeiro: Instituto 
Brasileiro de Geografia e Estatística; 2019 [citado 2020 maio 17]. Disponível em: https://www.ibge.gov.br/cidades-e-estados/ba/paulo-afonso.html

11. Prefeitura de Paulo Afonso. Novas instalações do Centro de Testagem e Aconselhamento [Internet]. 2018. Bahia: prefeitura de Paulo Afonso; 2018 [citado 2020 maio 17]. Disponível em: http://www.pauloafonso.ba.gov.br/ novo $/ \mathrm{p}=$ noticias $\& \mathrm{i}=7362$

12. Santos NJS, Sara AT, Silva SR, Buchalla CM, Laurenti R. $A$ aids no Estado de São Paulo. As mudanças no perfil da epidemia e perspectivas da vigilância epidemiológica. Rev. Bras. Epidemio [online]. 2002; 5(3),286-310. doi: $10.1590 /$ S1415-790X2002000300007

13. Soares R., Armindo RD, Rocha GA. A imunodeficiência e o sistema imunitário. O comportamento em portadores de HIV. Arq Med [online]. 2014; 28(4):113-121.

14. Arruda EF, Dias CM, Pastore DH, Thomé RCA, Yang HM. Modelo para as Interações entre Células de Defesa Contra o HIV. Proceeding Series of the Brazilian Society of Applied and Computational Mathematics [online]. 2015; 3(2)1-7. doi: 10.5540/03.2015.003.02.0019

15. Oliveira FS, Morais ALJ, Sobral MAS. Estudo epidemiológico da aids no período 2008-2015 no estado de Sergipe. Rev eletr Estácio Saúde [online]. 2019; 6(1):17-33.

16. Brito AM, Castilho EA, Szwarcwald CL. AIDS e infecção pelo HIV no Brasil: uma epidemia multifacetada. Rev Soc Bras Med Trop [online]. 2001; 34(2):207-217. doi: $10.1590 / \mathrm{S} 0037-86822001000200010$

17. Zambenedetti G, Silva Ran. Descentralização da atenção em HIV-Aids para a atenção básica: tensões e potencialidades. Revista de Saúde Coletiva [online]. 2016; 26(3):785-806. doi: 10.1590/ S0103-73312016000300005

18. Silva BEB, Santos VS, Santos IER, Batista MVA, Gonçalves LLC, Lemos LMD. Prevalence of coinfections in women living with human immunodeficiency virus in Northeast Brazil. Journal of the Brazilian Society of Tropical Medicine [online]. 2020; 53:e20190282. doi: 10.1590/0037-8682-0282-2019

19. Cabral JVB, Santos SSF, Oliveira CM. Perfil sociodemográfico, epidemiológico e clínico dos casos de hiv/aids em adolescentes no estado de Pernambuco. Revista Uniara [online]. 2015.
20. Taquette SR, Andrade RB, Vilhena MM, Paula MC. A relação entre as características sociais e comportamentais da adolescente e as doenças sexualmente transmissíveis. Rev Assoc Med Bras [online]. 2005; 51(3):148-52. doi: $10.1590 / S 0104-42302005000300015$

21. Martinez EZ, Zucoloto ML, Galdino G, Nunes AA, EAS. Spatiotemporal distribution of acquired immunodeficiency syndrome incidence in Brazil between 2012 and 2016. Rev Soc Bras Med Trop [online]. 2020; 53:e20190086. doi: 10.1590/0037-8682-0086-2019

22. Prefeitura de Paulo Afonso. CTA/SAE, serviço que faz a diferença na vida das pessoas [Internet]. 2011. Bahia: prefeitura de Paulo Afonso; 2011 [citado 2020 maio 17]. Disponível em: http://www.pauloafonso.ba.gov.br/ novo/?p=noticias\& $=1496 \#$

23. Guimarães MDC, Carneiro M, Abreu DMXI, França EB. HIV/AIDS Mortality in Brazil, 2000-2015: Are there reasons for concern?. Rev Bras Epidemiol [online]. 2017; 1:182-190. doi: 10.1590/1980-5497201700050015

24. Pereira GFM, Sabidó M, Caruso A, Benzaken AS. Decline in reported AIDS cases in Brazil after implementation of the test and treat initiative. BMC Infectious Diseases [online]. 2019; 19:579. doi: 10.1186/ s12879-019-4018-z

25. Passos DF, Bremm JM, Silveira LL, Janstch MH, Silva JLG, Disconzi $\mathrm{E}$, et al. CD4/CD8 ratio, comorbidities and aging in treated HIV infected individuals on viral suppression. J Med Virol [online]. 2020. doi: 10.1002/jmv.25911

26. Ganesan A, Chattopadhyay PK, Brodie TM2, Qin J, Gu W, Mascola JR, et al. Immunological and Virological Events in Early HIV Infection Predict Subsequent Rate of Progression. J Infect Dis [online]. 2010; 201(2): 272284. doi: $10.1086 / 649430$

27. Li $Y$, He C, He Z, Zhong M, Liu D, Liu R, et al. AIDS prevention and control in the Yunnan region by $T$ cell subset assessment. PLoS One [online]. 2019; 14(4):e0214800. doi: $10.1371 /$ journal.pone. 0214800

28. UNAIDS. 90-90-90: uma meta ambiciosa de tratamento para contribuir para o fim da epidemia de AIDS [Internet]. Genebra; 2015 [citado 30 Jul. 2020]. Disponível em: https://unaids.org.br/wp-content/ uploads/2015/11/2015_11_20_UNAIDS_TRATAMENTO_ META_PT_v4_GB.pdf 


\section{Declaração de conflito de interesses}

Os autores declaram ausência de conflitos de interesse.

\section{Contribuições dos autores}

Medeiros DA e Takenami IO contribuíram na concepção e delineamento do estudo, análise e interpretação dos dados; redação ou revisão crítica relevante do conteúdo intelectual do manuscrito. Palácio MAV e Gois LL contribuíram com a redação ou revisão crítica relevante do conteúdo intelectual do manuscrito. Todos os autores aprovaram a versão final do manuscrito e declaram-se responsáveis por todos os aspectos do trabalho, garantindo sua precisão e integridade.

\section{Fonte de financiamento}

Não se aplica

\section{Agradecimentos}

Nossos agradecimentos a Isaque Oliveira Braga, estudante de medicina da Universidade Federal do Vale do São Francisco (UNIVASF), campus Paulo Afonso (Bahia), pela cessão de direitos de uso da imagem da Figura $2 \mathrm{~A}$ e ao Centro de Testagem e Aconselhamento/ Serviço de Assistência Especializada (CTA/SAE), pelo apoio logístico e colaboração na realização da pesquisa.

Autor correspondente:

Iukary Takenami

iukary.takenami@univasf.edu.br

Editor:

Prof. Dr. Felipe Villela Gomes

Recebido em: 06/08/2020

Aprovado em: 14/10/2020

(c) (i) Este é um artigo publicado em acesso aberto (Open Access) sob a licença Creative 